vidual readings, of which only the mean is useful. I do not believe that, since the year 1835 at least, any person in the world except ourselves has actually taken a mean. As each reading contains 3 or 4 figures, there are printed in each year something like I50,000 useless figures. Reliance must be placed somewhere on the skill and fidelity of the observer, and (considering the severity with which every figure of transit-wire and of circle-microscope, and of their means, is examined here) this reliance may be placed at least as well on the means as on the originals. I have reason to think that the bulky volume of nearly 900 pages, might be reduced to about three-fifths of its present size by omitting those originals.

"I would submit for the consideration of the Board whether it might not be advantageous that they should hold a special meeting to consider the subjects which I have indicated. The length of time at an ordinary visitation, and the circumstances under which the Board meets, are not sufficiently favourable for the discussion of broad questions of Observatory policy."

\section{HOLTZ'S ELECTRICAL SHADOWS}

$\mathrm{I}$ an extremely elegant series of researches Prof. W. Holtz of Berlin has lately brought to light the existence of a new class of electrical phenomena, to which their distinguished discoverer has assigned the name of Electric Shadow-figures. Though nearly six months have elapsed since they were described in the Proceedings of the Göttingen Gesellschaft der Wissenschaften, no detailed account of them has appeared in any English journal. Yet the shadow-figures are remarkably easy to produce, and the whole research is of extreme simplicity, as very little apparatus is required beyond the simplest odds and ends to be found in every physical laboratory, the only large instrument necessary being one of Holtz's electrical machines.

The fundamental arrangement is that shown in Fig. I. From the discharging-rods of a Holtz machine the brass balls are removed. To the left rod there is attached in place of the ball a circular disk of some 10 to 20 centimetres diameter, having its front face either flat or slightly concave. To the right rod a point is fixed, and it is drawn back till from 6 to 15 centimetres distant from the disk. A piece of silk or satin of the same size as the front surface of the disk is laid upon it while the machine is in action, it adheres of itself to the surface, and the preparation is now complete. Before the silk is placer over the disk a small "brush" discharge of blueish light is all that can be distinguished at the point of the righthand discharging-rod: but this now changes to a very faintly glowing star. At the same moment the central region of the silk-covered disk exhibits a peculiar glimmering light over a well-defined circle. The utmost care is needed to shut out all extraneous light from the room, otherwise the delicate appearances which follow cannot be seen. It is upon this circular patch of feeble light that the shadow-figures are thrown. Its pale gleam becomes more vivid when the machine is more energetically worked : it enlarges in area but diminishes in brightness as the point is drawn back from it, and contracts with an accompanying increase in brightness as the point is brought nearer. It is possible to obtain a similar glimmering surface also upon a large metal ball covered with silk and attached to the rod in place of the concave disk, or instead a screen made of two or three folds of silk stretched over an ebonite ring may be placed between the two discharging-rods, the ends of both being furnished with points. In each case it is important that the silk be without crease or wrinkle, otherwise an evenly illuminated disk of light will not be obtained.

If now a body of definite outline of form be interposed between the point and the disk, an electrical shadow of it will be cast upon the luminous circle. These shadows are truly electrical, not optical, for all bodies do not cast them, and, more curious still, different bodies though of the same shape may cast differently shaped shadows. Conductors of electricity cast well-defined shadows, and so do semi-conductors, such as wood and cardboard. True insulators of small dimensions cast no shadows. The insulation or non-insulation of the conducting bodies makes no difference in their shadow-giving power. A cross cut out of cardboard casts (as in Fig. I) a well-defined shadow at the centre of the field, but the exterior portions are somewhat hazy. An ebonite cross casts no shadow. A cross made up of two strips, one of cardboard, the

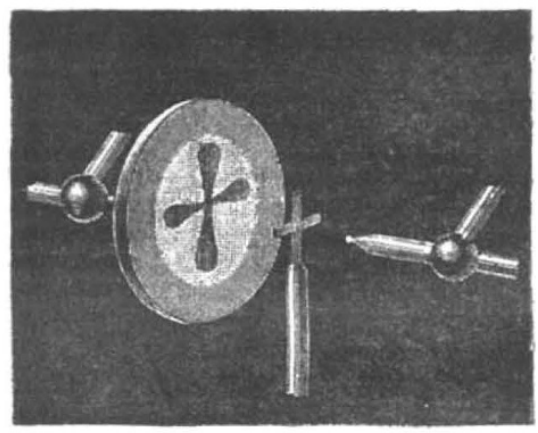

F1G. 1.-Electric shadow cast by a cardboard cross.

other of ebonite, fastened with shellac, casts only a single bar of shadow. Rings of tinfoil, cardboard, or wire also cast shadows. Such small objects are conveniently held by attaching them to the end of glass rods. The size of the shadows increases if the objects are displaced from their central position to right or left. A strip of card or thin metal casts the same shadow whether it be held broadside or edgeways in the field. A wire grating having 5 millimetres width between the bars obscures the field like an opaque body. Breathing on a strip of ebonite or glass renders its surface a feeble conductor, and it casts a transient shadow. A glass rod heated at one point casts a shadow at the heated point, the shadow dying out as the

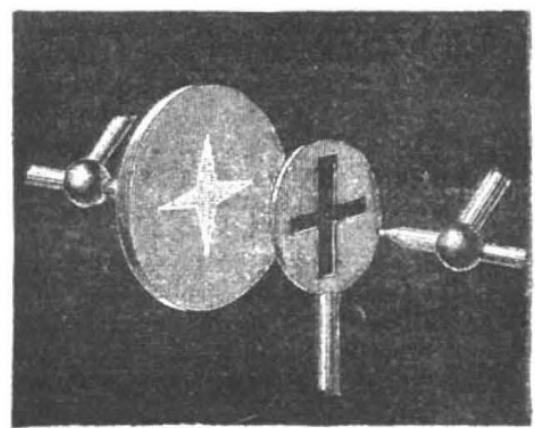

Fig. 2.- uminous figure projected through aperture in cardtoard screen.

rod cools. No shadow is cas* by a conductor whose surface is completely covered by insulating material, such as a shellac-covered wire or a glass tube containing water, but dry externally. The smoke ascending from a cigar casts moving shadows upon the silken screen. If a small ball be fixed upon the left discharging-rod in place of the point the shadow on the silk is poor, but a second shadow is observed upon the surface of the ball, and this is excessively small, reminding one of the diminished erect virtual optical image in a small polished ball. This one experiment succeeds best if the ball be made the positive con- 
ductor. For the other experiments it makes little difference whether the electrification of the point be positive or negative, except that when the point is positively electrified the illuminated surface is a little larger than when negatively electrified. A larger disk of light can also be obtained by working the machine at a greater velocity, but at the same time the shadows are rather smaller.

Prof. Holtz has also obtained the inverse phenomenon of luminous-figures by two different means. If two pointed needles are fixed horizontally side by side upon the discharging rod opposite to the disk, there appears a vertical streak of light across the glimmering field. If the needles be replaced by a horizontal strip of metal with its edge directed toward the disk, a vertical bright streak is also produced. A short metallic tube affixed to the discharging rod produces on the disk a dark central spot surrounded by a nebulous bright ring. The second kind of luminous-figures is produced in the manner shown in Fig. 2, where a circular disk of metal or cardboard having a central aperture of recognisable form is interposed between the point and the screen. The result is a luminous image of the aperture which, though well-defined at the middle, is marred at the outer regions, the shadowed portions appearing to encroach more upon the illuminated parts as we pass to the peripheral region. The following experiment is curious :-If a square aperture be chosen, the luminous figure projected on to the silken surface shows well-defined corners; but if a small round disk of card be interposed between the discharging point and the square aperture the luminous square on the silken screen at once exhibits rounded corners.

Another interesting point connected with the shadowfigures is that they can be fixed in a temporary manner, like Lichtenberg's figures, by sifting upon the silken surface lycopolium-powder or other fine dust. This collects chiefly upon the contours of the figures, though under certain conditions the luminous and shadowed parts exhibit a contrasted density in the deposit of dust upon them. These dust-figures have an obvious relation with those obtained by Wiedemann from the discharge of Leyden jars through a pointed conductor against the surface of various bodies. It would be interesting to ascertain whether by this process also shadow-figures can be proluced.

In explanation of these appearances Prof. Holtz propounds the view that they are due to a rectilinear discharge of electrified particles from the point of the discharging-rod, the discharge taking the general form of a cone, but in which the paths of the outermost particles diverge more widely as they approach the silken disk. The function of the silk he believes to be to retard the discharge, and thereby to increase the electric density on the point. The conducting bodies which are interposed in order to produce shadows act therefore by deflecting the flying particles from their path, either by absorbing or reflecting them. In many cases this action would appear to be a repulsion, since the shadows are always larger than the objects, and suffer more distortion by enlargement nearer the borders of the disk. To explain the production of the double shadows, the rather doubtful hypothesis is advanced that there is a rectilinear discharge of particles in both directions at once.

Quite independently of these observations, the same kind of phenomena have been investigated in America by Messrs. Fine and Magie of the Green School of Science, Princetown, N.J. These experimenters were aware of the existence of shadows on the positive discharging knob, but believed that they were the first to discover the existence of a negative shadow. They found however that non-conductors cast the best shadows, and added the interesting observation that the lines of electrical action were deflected by the presence of a conducting body at the side of the field, and the form of the shadow correspondingly altered. Negative shadows were also observed, they remark, some years ago by Prof. C. A. Young.

These shadow-figures become doubly interesting when compared with the "molecular-shadows" obtained by Crookes from electric discharges in high vacua Further experiments are probably needed before their precise nature is fully known.

S. P. T,

\section{BEN NEVIS OBSERVATORY.}

$A$ PROPOSAL was made a year or two ago to erect an observatory on the top of Ben Nevis for meteorological observations, but nothing was done owing to the want of the necessary funds. A committee has been formed, however, within the last few months for the purpose of raising a testimonial to Mr. David Hutchison, who did so much in opening up the West Highlands to tourists with his steamboats, and we observe that it is proposed that the testimonial take the shape of an observatory on the top of Ben Nevis. The committee is a large and influential one, and the proposed scheme has every appearance of being successfully carried out.

In the meantime the Scottish Meteorological Society has commenced daily observations on Ben Nevis, which will be continued during the summer months-the Society having accepted a handsome offer by Mr. C. L. Wragge, who has had experience of such work, to climb to the top of Ben Nevis every morning in time to make observations there at 9 a.m. A complete set of the best instruments has been procured. The barometer (a Fortin), is an excellent instrument, and is constructed to read as low as 23.000 inches, in the procuring of which Mr. Scott of the Meteorological Office kindly gave his assistance. On Tuesday, May 3r, Mr. Wragge, with Mr. Livingstone, of the Public Schools, and nine workmen ascended the mountain, and the instruments were fixed and secured in proper positions, and all, including the barometer, were found to be in good working order. The regular observations began on the following day, June I, Mr. Wragge being at his post on the top of the Ben, 4405 feet above the sea, at 9 a.m. He remains an hour at the top, and makes three observations, viz. at $9,9.30$, and 10 a.m. Even during the stormy weather of Saturday last, the observations were made and the observer back to Fort William at I.30 p.m., on which occasion the temperature at the top was as low as $28^{\circ}$.

Simultaneously with the Ben Nevis observations, a complete series of observations are also made near sealevel by Mrs. Wragge. These observations, together with the observations made at the neighbouring stations of Roy Bridge, Corran, Landale, Airds, Lismore, and Dalnaspidal ( 1450 feet above the sea), will give the data required in dealing with some of the more important problems in meteorology.

\section{NOTES}

Amongst the few existing institutions for the higher education of women, perhaps none has done better work during the last thirty years in a quiet, unobtrusive fashion than Bedford College, York Place. The recent action of London University in opening its degrees to women has given a fresh impetus to women's education; and Bedford College has set itself the task of providing the training for which London Universty offers only the test-a task in which it has already acbieved such success as to give a sure promise of a brilliant future. The funds, however, at its disposal, derived mainly from the bequest of the late Mrs. Reid, prove inadequate to the strain thus put on its resources, and an appeal for support is now being circulated which deserves the attention of the friends of education. In that appeal details of the work and aim of the College will be found. Space will only allow us to add that subscriptions will 